\title{
SCHELLING Y NIETZSCHE. DE LA INTUICIÓN INTELECTUAL Y LA INTUICIÓN ARTÍSTICA DE LA LIBERTAD
}

Schellling and Nietzsche.

\section{About the intellectual Intuition and the artistic Intuition of Freedom}

\author{
Alejandro Rojas Jiménez \\ Universidad de Málaga
}

«Dem Menschen aber ist seine Geschichte nicht vorgezeichnet, er kann und soll seine Geschichte sich selbst machen.» (SW I/1, 470)

Resumen: Se analizan en este trabajo las filosofías de Schelling y Nietzsche mostrando una intuición de libertad compartida en ambos autores, que el idealista estaría más preocupado por tematizar (no enfrentándose a -incluso no reconociendo- sus consecuencias), mientras que Nietzsche, por el contrario, asumiría sin tematizar dicha intuición de libertad, más preocupado por extraer sus consecuencias.

Palabra Clave: libertad - decisión - Schelling - Nietzsche - mal - miedo

ABSTRACT: The philosophies of Schelling and Nietzsche are discussed in this paper, highlighting a certain intuition of freedom that both authors share; although the idealist would be more concerned with thematizing it (not confronting, not even acknowledging, its consequences), whereas Nietzsche, on the contrary, would assume that the intuition not-thematized of freedom, more concerned with deriving its consequences than with philosophically thematising it.

Keyswords: Freedom - Decision - Schelling - Nietzsche - Evil - Fear 


\section{INTRODUCCIÓN: NiETZSCHE Y SCHELLING}

\section{I.1. El SCHELling DE NiETZSCHE.}

Nietzsche sólo hace referencia a Schelling alrededor de una quincena de veces, y en cada caso dicha referencia es en realidad una referencia general que no muestra por sí misma un conocimiento suficiente de la filosofía de Schelling. Su acercamiento es siempre general. Es tratado sencillamente como un idealista más y sólo en pocos casos, siempre sin profundidad, se refiere a un rasgo concreto de su filosofía: la intuición intelectual.

Siendo así, bien creo que podríamos decir que Schelling es, para Nietzsche, el filósofo de la intuición intelectual. Sobre ésta, su origen, o su relación con Fichte y Kant, nada dice, por un lado porque no parece interesarle, pero por otro -me temo, porque poco parece saber al respecto. Se podría decir así: lo que le interesa es que la intuición intelectual designa una capacidad (Vermögen), pero le molesta de esta intuición intelectual que es precisamente intelectual. Nietzsche piensa la intuición contra la razón, contra lo intelectual: ${ }^{2}$ la piensa artística. ${ }^{3}$ Esta referencia a una intuición artística la encontramos en abril de 1871, y por consiguiente, mucho antes que la primera referencia, en junio de 1885, a la intuición intelectual de Schelling. ${ }^{4} \mathrm{Y}$ por ello cabe sentenciar que para comprender la intuición artística en Nietzsche no es necesario conocer la intuición intelectual de Schelling. Lo cual no impide decir que aquí, como en otros aspectos, Nietzsche está más cerca de Schelling de lo que él sospecha.

\section{I.2. Algunos anÁlisis de las CERCANíAS ENTRE AMbos AUtORES.}

A propósito de aquella cercanía cabe destacar algunos estudios muy interesantes. K. Löwith, por ejemplo, compara la noción de «eterno retorno»y «amor fati» ${ }^{5}$ en ambos autores. ${ }^{6} \mathrm{M}$. Heidegger, por su parte, compara en ambos autores el ser entendido como querer. O. Kein compara la dualidad ApoloDionisos, que se encontraba ya jugando su papel en la idea de productividad de Schelling. ${ }^{7}$ Mucho más atrevido es M. Frank, quien considera, en esta línea, que de hecho hay una dependencia de Nietzsche con respecto a Schelling en

1 Cf. FP III 34[82]; JGB §11.

2 Cf. WL $\$ 2$.

3 Cf. FP I 7[159].

4 Cf. FP III 34[82].

5 No se olvide que el propio Nietzsche afirma que su fórmula para la grandeza del hombre es el amor fati. Cf. EH «El caso Wagner» §54.

6 Cf. K. Löwith, Nietsches Philosophie der ewigen Wiederkehr des Gleichen, Stuttgart: Meiner, $1956,151,83 \mathrm{~s}$.

7 Cf. O. Kein, «Das Apollinische und Dionysische bei Nietzsche und Schelling», en Neue Forschungen, Ab. Philosophie, Bd. 6, Berlin: Junker und Dünnhaupt, 1935. 
su interpretación del Dionisos de los Eleusinischen Mysterien, ${ }^{8}$ sosteniendo incluso que Nietzsche habría citado (sin decir) algún pasaje de Schelling. ${ }^{9}$ A mí me parece que efectivamente en este punto dionisíaco es donde ambas propuestas filosóficas más nos recuerdan la una a la otra. Para un estudio pormenorizado al respecto remitiré al trabajo de Wilson. ${ }^{10}$ Yo, desde luego, y a diferencia del último trabajo al que se ha hecho mención, me inclino a pensar, sin perder de vista los estudios citados, que la cercanía se produce entre filosofías que son en realidad independientes entre sí. Lo particular de este trabajo es que no buscaré esas cercanías en términos de influencias, dependencias o similitudes. Quiero encontrar la relación entre ambos a partir de aquello que los separa: su actitud. O dicho de un modo más preciso: quiero entender lo que lo separa (su actitud) como consecuencia de una intuición compartida. Una intuición que es una intuición de libertad.

\section{I.3. DOS FILOSOFÍAS DISTINTAS, UNA MISMA INTUICIÓN DE LIBERTAD.}

En Zur Genealogie der Moral Nietzsche hace referencia a una gran decisión que hará de la voluntad una voluntad nuevamente libre. ${ }^{11}$ De la filosofía de Nietzsche propongo centrarme para este estudio en el papel de esta decisión, pues me parece que es el término que mejor define su intuición de la libertad. Ser libre se ha entendido de muchas maneras, y la filosofía de Nietzsche bien puede ser presentada como una filosofía que expresa cierta intuición de libertad como decisión. La gran decisión no es un hecho. No podría serlo. La gran decisión es una opción, la de decidir decir sí, o no, a la transvaloración de todos los valores. ${ }^{12}$ Consciente de dicha dificultad, Nietzsche avisa que esta decisión será la del hombre del futuro, ${ }^{13}$ y que su obra debe ser interpretada como un anzuelo para ese hombre del futuro. ${ }^{14}$ Nos volvemos a encontrar en Ecce homo la afirmación nietzscheana de que su gran destino es provocar una especie de crisis y suprema decisión. ${ }^{15}$ Ésta, como las anteriores, no son referencias que debamos pasar por alto, porque a

8 Cf. M. Frank, Der kommende Gott. Vorlesungen über eine neue Mythologie, Frankfurt a.M.: Suhrkamp,1982, 344-46 y en Gott im Exil. Vorlesungen über die neue Mythologie, Krankfurt a.M.: Suhrkamp, 1988, 55-58.z

9 Compara en Gott im Exil el pasaje de Nietzsche de WW I, 61 con el pasaje de Schelling de Sämmtlichen Werken (en adelante SW) (ed. August Schelling), Stuttgart y Augsburgo: G. Cotta, 1856, vol. II/3, pp. 480-48, para concluir que Nietzsche fue un lector inconfesado de Schelling.

10 Cf. J.E Wilson, Schelling und Nietzsche. Zur Auslegung der frühen Werke Friedrich Nietzsches, Berlin/New York: Gruyter, 1996.

11 Cf. GM II $\$ 24$.

12 Cf. EH «Más allá del bien y del mal» §1.

13 Cf. GM II $\$ 24$

14 Cf. EH «Más allá del bien y del mal» §1.

$15 \mathrm{Cf}$. EH «Consideraciones intempestivas» $\$ 2$. 
mi juicio señalan un aspecto central de la filosofía de Nietzsche: que tiene que ser interpretada como el intento de conducir hacia esta gran decisión.

Estoy intentando en todo momento evitar emplear la expresión «noción de libertad», porque se trata justamente de hacer ver que Nietzsche no alcanza a tener siquiera una intuición intelectual de dicha libertad. Si acaso llega a tener de la libertad, me serviré de su expresión, una «intuición artística» ${ }^{16}$. Esta expresión es muy significativa: la intuición artística no sirve para entender mejor, para profundizar (en este caso en comprensión de la libertad), sino para dejarse llevar por ella extrayendo sus consecuencias prácticas.

Intentaré mostrar a continuación que la misma intuición de libertad funciona en Schelling. Pero él no tiene de la misma una intuición artística, sino $-y$ utilizo ahora la expresión empleada por el propio Schelling para referirse a la autoconciencia inmediata del espíritu a través del querer- una «intuición intelectual» ${ }^{17}$, en la que Schelling quiere profundizar y pensar, sin atender a las consecuencias prácticas de dicha intuición.

\section{LA CRÍTICA NIETZSCHEANA A LA «INTUICIÓN INTELECTUAL» DE SCHELLING}

Nietzsche no conocía la filosofía de Schelling. Para él, Schelling, como ya he comentado, era poco más que el filósofo de «la intuición intelectual», y no llega a advertir que esa intuición intelectual es, en realidad, una intuición intelectual de la libertad según la cual tomamos conciencia de la realidad del querer (como un Factum habría dicho Kant). ${ }^{18}$ Un querer que ya para el primer Schelling era absoluto. ${ }^{19} \mathrm{Si}$ Nietzsche hubiera leído a Schelling se habría dado cuenta de que aquel «Yo» al que se tenía acceso desde una intuición intelectual nunca fue otra cosa que puro acto, puro hacer $\mathrm{y}$, por ende, pura voluntad. ${ }^{20}$ Una voluntad que recibirá el nombre, en su filosofía de la naturaleza, de «productividad incondicional», al pensarla en contraposición con los productos (donde ya deja de ser productiva).

Y así, aunque según Nietzsche poco separa a Schelling de los idealismos de Fichte y Hegel, e incluso de Jacobi, cabe decir que el juicio de Nietzsche

16 «Aquella fuerza vigorosa y viril, y su lenguaje que oscila hacia la profunda intuición artística» FP I 196: 7[159].

17 «Die Quelle des SelbstBewuustseyns ist das Wollen. Im absoluten Wollen aber wird der Geist seiner selbst unmittelbar inne, oder, er hat eine intelectuale Anschauung seiner selbst» Allgemaine Uebersicht, AA I, 4, 128.

[F. W. J. Schelling, Historisch-kritischen Schelling Ausgabe der Bayerischen Akademie der Wissenschaften (en adelante AA) (ed. Baumgartner, Jacobs, Jantzen, Krings, Zeltner), Stuttgart-bad Cannstatt: Frommannn-holzboog, vol. I, 4, p. 128, (SW I, 401).

18 Cf. I. Kant, Kritik der praktischen Vernunft (en adelante KpV), p. 96.

19 Cf. M. Frank, Eine Einführung in Schellings Philosophie, Frankfurt a. M.: Suhrkamp, 1985, p. 42.

20 Cf. F.W. J. Schelling, System, SW III, 368. 
es infundado. Sin entrar en profundidad, habría que resaltar al menos que a Nietzsche poco parecen importarle, seguramente por desconocerlas, ${ }^{21}$ las peleas que éste tuvo con los tres filósofos mencionados, y que en el caso de Jacobi acabaron incluso con la expulsión de éste de la Academia de las Ciencias. ${ }^{22}$

Y a pesar de todo lo dicho, a tenor de la época y el contexto de la obra de Schelling, tenderíamos a pensar que de todas formas el desarrollo de esta filosofía no debería ser - a pesar de todo- del agrado de Nietzsche, contrario al fin y al cabo a toda expresión idealista. Pero conviene plantearse qué tipos de filosofías pueden ser consideradas nietzscheanas.

Sin necesidad de llegar a afirmar que de algún modo, por lo que supone cierta superación del pasado, todo filósofo es un poco nietzscheano, resulta muy sugerente preguntarse qué filosofías guardarían cierto "aire de familia» con la filosofía de Nietzsche; qué clase de filosofía podría hacer aquel que quedara atrapado en el «anzuelo» de la filosofía nietzscheana.

Ahora bien, si la filosofía nietzscheana no puede concretarse nunca en un sistema concreto, como parece ser lo más acertado decir, más bien parece que de lo que podemos hablar es en todo caso de continuaciones nietzscheanas posibles capaces de adquirir distintas formulaciones. Podríamos preguntarnos incluso si no cabría encontrar ciertas «actitudes» -habría que decir en este caso- nietzscheanas en el pasado. En Grecia, por ejemplo, la sofística parece ser una actitud nietzscheana ante el intelectualismo en las figuras de Protágoras o Gorgias. Aunque puede resultar polémico, en algún sentido cabe decir que, frente al intelectualismo escolástico, el voluntarismo medieval de Ochkam parece ser también un actitud parcialmente nietzscheana, pues hablaban - aunque refiriéndose a Dios- de una voluntad con capacidad para el bien y el mal, y por ende más allá del bien y del mal. Es en un sentido muy similar en el que el idealismo de la libertad de Schelling, especialmente en su filosofía tardía, esa que desembocará finalmente en la filosofía de la mitología y la filosofía de la revelación, el de Leonberg, propone frente al idealismo intelectualista de Hegel, si es que se me permite decirlo así, un idealismo del querer. Un idealismo, si se prefiere, dominado siempre por la idea de que el querer es «la condición más alta de la autoconciencia» ${ }^{23}$ y de que toda conciencia intelectual presupone ya un acto libre que precede a esta reflexión sapiente de sí. ${ }^{24}$

21 Es muy probable que Nietzsche desconociera la biografía de Schelling y, mucho más la que se considera como la Spätphilosophie Schellings.

22 Cf. W. G. Jacobs, Schelling lesen, Stuttgart-Bad Cannstatt: Frommann-Holzboog, 2004, p. 33.

23 F.W. J. Schelling, Allgemeine Übersicht. AA I, 4, 121 (SW I, 394).

24 Cf. ibid., AA I, 4, 126. (SW I, 399ss.) 
Si esto es así, sería un idealismo de cierta actitud nietzscheana. Esto «nietzscheano» residiría concretamente en lo siguiente: Schelling también está convencido de que la decisión es irreductible al conocimiento. ${ }^{25}$ Entiende la libertad como una «decisión originaria» ${ }^{26}$ que desencadena la historia del yo. Una decisión que está, desde luego, más allá del bien y el mal.

Y si todavía Scoto y Ockham sencillamente sacan las consecuencias para una libertad entendida previamente como omnipotencia, en Schelling el gesto es algo distinto: quiere pensar la libertad real y viva, sin partir de una idea formal de libertad. ${ }^{27} \mathrm{Y}$ entonces, descubre no sólo que la libertad es elegir lo uno o lo otro, sino que al poder elegir lo uno o lo otro se produce una «elección de sí», un acto de autorrevelación: que en el acto «necesario» de decisión la libertad se manifiesta como querer originario al tiempo que se «escinde» su unidad en dos principios irreconciliables. No estamos pues ante una verdad objetiva $^{28}$, sino tematizando la autoconciencia del querer que se lleva a cabo en el acto de la voluntad, ${ }^{29}$ cuando aquel poder querer cualquier cosa se realiza en el querer, aun cuando al querer sólo se puedan querer cosas concretas.

Al hacerlo teóricamente, a diferencia de Nietzsche, puede sacar conclusiones y tesis que convendría analizar para saber en qué medida podrían servirnos como herramientas conceptuales para entender la «voluntad de poder» nietzscheana, ya que en Nietzsche, más que un concepto expresable, es una intuición que se utiliza para afirmar la productividad frente a los productos. Los conceptos que utilizará Schelling no serán desde luego conceptos al uso para una realidad que él mismo califica, desde bien temprano, como «inconcebible». ${ }^{30}$ Pues: ¿cómo pensar con conceptos lo que es actividad y previo a ellos?

Efectivamente, para Schelling, pensar la libertad significa entenderla como vida ${ }^{31}$. Se trata, es cierto, de la vida de Dios (o si se quiere de un Dios vivo), pero en cualquier caso esto significa pensar a Dios sin conceptos,

25 Cf. A. Leyte, Las épocas de Schelling, Madrid: Akal, 1998.

26 Cf. A. Carrasco, «Elección y decisión»: Daimon, Suplemento 2 (2008), 347-354.

27 Sus críticas al idealismo en general son en este punto fuertes y contundentes, tanto como lo será posteriormente Nietszche. Cfr. F.W. J. Schelling, Freiheitsschrift, SW VII, 352.

28 En lugar de encontrarse con «cosas» (cf. Freiheitsschrift, SW VII, 349) se encuentra con una única realidad (panteísmo, cf. Freiheitsschrift, SW VII, 339-40) cuyo ser consiste en querer (cf. Freiheitsschrift, SW VII, 350).

29 F.W. J. Schelling, Allgemeine Übersicht. AA I, 4, 122. (SW I, 395.)

30 Cf. F.W. J. Schelling, Allgemeine Uebersicht. AA I,4. 127. (SW I, 400.)

31 Cf. F.W. J. Schelling, Freiheitsschrift SW VII, 399; cf. T. Buchheim, «Metaphysische Notwendigkeit des Bösen. Über eine Zweideutigkeit in Heideggers Auslegung der Freiheitsschrift», en Zeit und Freiheit. Schelling-Schopenhauer-Kierkegaard-Heidegger. Akten der Fachtagung der Internationalen Schelling-Gesellschaft, Budapest, 1999, 183-191, especialmente 185-187. 
pensarlo como un acto de decisión libre, ${ }^{32}$ un acto de decisión libre más allá del bien y del mal.

Es cierto que no dice propiamente que esté más allá del bien y del mal, pero sí que es capaz del mal, y debe asumirse que sólo puede haber dicha capacidad porque se sitúa por encima del bien y del mal o, dicho de otra manera, porque la decisión no se subordina a ninguna necesidad (ni siquiera la de lo bueno). Al pensar la decisión en estos términos, sin subordinarla a discursos moralistas y enfrentándose a la tradición (si es que aceptamos la denuncia de Jacobi), lo que hace Schelling es tematizar el mismo tema que es central, aunque su tratamiento no sea teórico, en la filosofía de Nietzsche, a saber: la gran decisión, la del superhombre, las que nos pone ante las dualidades: moral de señores o de esclavos, voluntad de poder o de verdad, eterno retorno o concepción líneal de la historia, etc. ${ }^{33}$

No se trata de que Schelling sea un «nietzscheano» previo a Nietzsche. Tampoco un antecedente. La filosofía de Schelling nunca podría ser denominada propiamente nietzscheana. Pero al pensar la libertad en ese punto decisivo, está pensando teóricamente lo mismo que Nietzsche acepta: un querer originario que puede elegirlo todo. La voluntad de poder es una consecuencia práctica de la intuición intelectual de libertad como acto de decisión originario. Y la inversa: la libertad como acto de decisión originario es una intuición intelectual a la que se puede llegar sólo cuando partimos de cierta «intuición artística» de voluntad de poder.

Pasaré a continuación a demostrar esta tesis mediante un análisis comparado entre, lo diré así, las consecuencias que se pueden aceptar desde la filosofía nietzscheana, y las ideas alcanzadas por Schelling al profundizar en su intuición intelectual de libertad.

32 F.W. J. Schelling, Freiheitsschrift SW VII, 396.

33 En este punto me parece que sería necesario una fundamentación o exposición mayor de cómo se puede pensar la filosofía de Nietzsche como filosofía de la decisión, sin embargo, dicha exposición desbordaría los límites editoriales de un artículo científico, por lo que se llevará a cabo en otro lugar, convencido de que - a pesar de todo- esta ausencia, que obedece a motivos pragmáticos de circunstancias históricas, no evitará la comprensión general del propósito que se pretende. Lo diré si acaso con pocas palabras: lo que está en juego en el filosofar nietzscheano es nuestra propia existencia, nuestra voluntad. Si vamos a llevar una vida asumiendo cargas, barreras, límites a nuestro deseo y querer. O si por el contrario vamos a llevar la vida propia del superhombre, que está por encima del bien y del mal, que no subordina su querer al valor de ciertas verdades, y que vive al máximo el instante de su decisión. 


\section{LA VOLUNTAD DE PODER DE NiETZSCHE Y EL FREIHEITSSCHRIFT DE SCHELLING}

Voy a centrar mi análisis comparativo en el Freiheitsschrift, porque la filosofía de Schelling es muy compleja y sufre muchos cambios. ${ }^{34}$ Intentar defender una idea de libertad en la obra de Schelling podría significar ya en sí mismo un trabajo a parte. Me limitaré pues, a fin de concretar el análisis, a la obra donde su tratamiento de la libertad es más evidente y conocido, aun cuando tengamos que decir posiblemente que Schelling que nunca haya hecho otra cosa que pensar la libertad. De hecho, la estructura que aparece en este escrito, la relación entre naturaleza en Dios y Logos, es la misma, un hilo de Ariadna dice W. Jacobs ${ }^{35}$, que la que se puede encontrar bajo otras formas a lo largo de sus «épocas»: como razón y locura en las Weltalter, como finito e infinito en la Identitätsphilosophie, como productividad incondicionada y su cohibición en la Naturphilosophie, como filosofía positiva y negativa en su etapa final, etc.

Para resumir la «doctrina» de la libertad de Schelling expuesta en el Freiheitsschrift estableceré las siguientes ocho apreciaciones:

1) Que la libertad no está siendo pensada como una facultad subordinada a la razón, sino como un ser (el Ursein, el querer) sin fundamento (Ungrund), anterior a toda existencia determinada. ${ }^{36}$

2) Que la libertad encierra en sí misma una capacidad para el mal; no se subordina a ningún concepto ni a ninguna moral. ${ }^{37}$

3) Que la libertad sólo existe como actividad. ${ }^{38}$

4) Que la libertad originaria es inseparable de la interna necesidad que le obliga a determinarse y por la que distingue lo que existe del fundamento de la existencia: ${ }^{39}$ lo que existe sería la libertad determinada, el "fundamento" sería su originaria indeterminación.

5) Que no se puede pensar la libertad sin el tiempo de su propio proceso de determinación, en el que constantemente se ve empujada a rechazar lo concreto, es decir, a declarar la insuficiencia de lo finito. ${ }^{40}$

34 Cf. X. Tilliette, Schelling: Une philosophie en devenir, 2 vols., Paris: J. Vrin, 1969 (segunda edición aumentada, 1992).

35 Cf. Schelling lesen, op. cit., p. 69.

36 F.W. J. Schelling, Freiheitsschrift, SW VII, 406.

37 Cf. F.W. J. Schelling, Freiheitsschrift, SW VII, 352.

38 Cf. F.W. J. Schelling, Freiheitsschrift, SW VII, 351, y por eso no sólo el yo lo es todo, sino que todo es yo, porque todo lo efectivo tiene como fundamento esa actividad.

39 Cf. F.W. J. Schelling, Freiheitsschrift, SW VII, 373.

40 Schelling habla de un «Perpetuum mobile» (Freiheitsschrift, SW VII, 377) que desembocará en el conocido mythologische Prozess (cf. Philosophie der Mythologie, SW XI, 193) y en las edades del mundo. De momento se trata de resaltar la «eficacia universal» del mal (cf. Freiheitsschrif,t SW 
6) Que el origen de la libertad no es la pluralidad de opciones, sino la interna necesidad del ser libre que le obliga a determinarse. ${ }^{41}$

7) Que la libertad necesita del hombre, porque en él se realiza efectivamente. $^{42}$

8) Si se piensa esta libertad antes del primer acto de elección, entonces sólo podemos concebirlo como un ser sin predicado, como «indiferencia» ${ }^{43}$, es decir, un ser anterior a la distinción entre fundamento y existente. Está pensada aquí pues sólo como la unidad indiferente de los principios. ${ }^{44}$

Estas tesis son el resultado de haber profundizado en una intuición intelectual de libertad. No podemos encontrar tesis tan explícitas en Nietzsche, porque Nietzsche no quiere realizar este viaje. Lo cierto es que no se le espera en este camino, que es el camino de la teoría y la filosofía tradicional; en este caso bajo la forma de un idealismo de la libertad. Insisto en que no se pretende a continuación buscar las mismas ideas en Nietzsche, sino algo mucho más sutil: proponer que Schelling habría tematizado filosóficamente la misma intuición de libertad de la que Nietzsche (quien tendría de ella una intuición artística), en lugar de tematizar, se habría preocupado por extraer sus consecuencias prácticas.

Analicemos por separado si estas ocho tesis están a su modo en la obra de Nietzsche:

1. Tesis: la libertad -cuando se la piensa real y viva y, por consiguiente, con capacidad para el bien y para el mal- no se la piensa como una facultad subordinada a la razón, sino como un ser (el Ursein, el querer) sin fundamento (Ungrund), anterior a toda determinación.

Convendría precisar que esto no significa que no tenga fundamento. Schelling hablaría de la «necesidad interna» que le empuja a querer: el querer es sólo querer cuando quiere. Y aquí dos apreciaciones, por un lado que esto, aunque lo desconozca Nietzsche, había sido así en Schelling desde bien temprano: ya en Allgemeine Uebersicht consideraba que esa intuición intelectual que tenía el espíritu del «Yo» como querer absoluto consistía en

VII, 373) —en tanto que debe haber tentación al mal para «dar vida a los dos principios» (cf. Freiheitsschrift, SW, VII, 374).

41 En relación con el punto anterior, Schelling habla de un proceso de autoafirmación (cf. Freiheitsschrift, SW VII, 350) que tiene lugar como consecuencia de la necesidad tras querer («el ser es originario es querer», Freiheitsschrift, SW VII, 350) pasar de la Natur (abismo, esencia de Dios, fondo oscuro) al Logos (la luz de su propio abismo) (cf. Freiheitsschrift, SW VII, 405-6)

42 Cf. F.W. J. Schelling, Freiheitsschrift, SW VII, 411

43 Cf. F.W. J. Schelling, Freiheitsschrift, SW VII, 406.

44 Cf. F.W. J. Schelling, Freiheitsschrift, SW VII, 407. 
una intuición por la conciencia de sí en el hecho de querer. ${ }^{45} \mathrm{Y}$ por otro lado que este fundamento no es otra cosa que la necesidad interna del querer. El querer puede querer una cosa u otra (puede elegir cualquier cosa), pero el querer es sólo querer cuando quiere realmente. Pero éstos son puntos a tratar en las tesis que han sido numeradas como 3 y 6 . En esta ocasión considero que debemos retener la idea de que estamos ante una intuición de libertad no subordinada a la razón.

En la obra de Nietzsche, que la libertad (cuya realización es el querer) está siendo pensada como libre de razones, se puede vislumbrar en pasajes como aquel de Also sprach Zarathustra en el que dice que la libertad que él $\mathrm{ama}^{46}$ debemos pensarla liberada $\left(\right.$ befreit $\left.{ }^{47}\right)$. Liberada de conceptos significa también para él una libertad distinta a aquella de la que hablan los filósofos ${ }^{48}$ (nosotros añadiríamos: tradicionales), y que él critica como una ilusión. A mí me parece que esta libertad, pensada desde la inocencia pueril de la risa del niño, es esa libertad liberada de ideas, prejuicios, libre de responsabilidades, de ética, de moral... Es la libertad capaz del bien y el mal. Es en ambos casos una libertad que pone en juego un sentido que no se debe buscar fuera del acto mismo de su «decisión».

2. Tesis: la libertad encierra en sí misma una capacidad para el mal; no se subordina a ningún concepto ni a ninguna moral.

En este sentido diré que Nietzsche llega a trivializar lo malo (lo humaniza y desontologiza ${ }^{49}$ ), convencido de que es necesario «enfadarse» ${ }^{50}$ (no hay que olvidar que en alemán enfadarse es literalmente volverse malo, böse werden) para entender que a veces hay que elegir lo malo ${ }^{51}$ para adentrarse en el camino corvo que lleva al reino que está más allá del bien y del mal. ${ }^{52}$ Para Schelling, desde luego, la libertad no tiene porqué elegir el mal, le basta con que pueda hacerlo. En Nietzsche, dicho lo dicho, en su defensa del «mal» está claro que está implícita la posibilidad del mismo.

45 Cf. F.W. J. Schelling, Allgemeine Uebersicht. AA I, 2, 106 (SW I, 181.)

46 Cf. Za II «De los sacerdotes».

47 «El querer hace libres: esta es la verdadera enseñanza sobre la voluntad y la libertad — así os la enseña Zaratustra» Za II, OC IV 121.

$48 \mathrm{Cf}$. Za II «De los grandes acontecimientos».

49 Cf., por ejemplo, HH §§ 28 y 39.

50 SE $\S 4$. «Así pues, y hablando con franqueza: es necesario que alguna vez nos volvamos realmente malvados [recht böse werden] para que las cosas mejoren» SE, 4, OC I 782. Ese «recht böse werden» que el traductor vierte correctamente como "volverse malvado" debe ser entendido sin embargo en el sentido de «enfadarse en serio».

51 Cf. ZA I «De las alegrías y de las pasiones».

52 Cf. ZA IV «El despertar» §2. 
3. Tesis: la libertad, esa real y viva con capacidad para hacer el bien y el mal, sólo existe como actividad.

Nietzsche dice en un sentido similar, en los fragmentos póstumos, que la libertad de la voluntad es para él la actividad del pensamiento. ${ }^{53} \mathrm{Si}$ bien, no es una idea ausente en la obra publicada. También en los escritos publicados hace referencia a una voluntad que está pensada como "fuerza real", en el sentido de una fuerza de la voluntad (Willenskraft ${ }^{54}$ ) que se reconoce por sus efectos (Wirkungen) ${ }^{55}$. Es, en la también sobradamente conocida Zur Genealogie der Moral, cuando, al definir como voluntad de poder la esencia de la vida, se refiere al querer como principio y fuerza espontánea, y como acción (Wirkung) ${ }^{56}$ También podríamos mencionar otras obras anteriores en las que se refiere al ser como acción, como por ejemplo Morgenröthe ${ }^{57}$ Pero desde luego donde con más claridad se refleja este asunto es en Jenseits von Gut und Böse, donde habla de un querer que actúa, efectivo; llegando a acuñar la expresión Willenswirkung. ${ }^{58}$ No es en vano que se use Wirkung en lugar de $A k t$, porque esa efectividad es la única real (wirklich), incluso la única realidad (Wirklichkeit).

Que la libertad en Schelling no está pensada como principio, sino como acto, es un lugar común de la literatura especializada sobre Schelling. ${ }^{59}$ Que no estamos hablando de ideas, sino de un acto, es lo que permite entender la posibilidad del mal: la posibilidad del mal sólo es real en el acto de la decisión.

4. Tesis: la libertad es inseparable de la interna necesidad que le obliga a determinarse y por la que distingue entre lo que existe y el fundamento de la existencia: ${ }^{60}$ lo que existe sería la libertad determinada, el «fundamento» sería su originaria indeterminación.

Con respecto a este punto resulta clarividente en aquel extracto, también de Jenseits von Gut und Böse, en el que dice que necesidad y libertad deben ser pensadas como una unidad. ${ }^{61}$ Ahora bien, en Menschliches Allzumenschliches Nietzsche es rotundo cuando dice que todo es necesario según el «nuevo

53 Cf. FP I 7[157] y 7[174].

54 «en definitiva, hemos de arriesgar la hipótesis de si, allí donde son reconocidos "efectos", no es la voluntad la que actúa sobre la voluntad — y de si todo acontecer mecánico, en la medida en que actúa sobre la voluntad, no es justamente una fuerza de la voluntad, un efecto de la voluntad» MBM §36, OC IV 322.

55 «la cuestión es si nosotros realmente reconocemos que la voluntad es algo que produce efectos» ibid.

56 Cf. GM II §12.

57 Cf. A $\$ 121$.

58 Cf. MBM $\$ 36$.

59 Cf. W. G. Jacobs, Schelling lesen, op. cit., p 108.

60 Cf. F.W. J. Schelling, Freiheitsschrift, SW VII, 373.

61 Cf. MBM §213. 
conocimiento» ${ }^{62}$; el de su «filosofía», esa según la cual todo es inocencia. ${ }^{63}$ Claro que está pensando en la justificación de la vanidad, el egoísmo, el deseo, el placer, pero es que entender bien lo que dice Schelling significa justamente eso: esa necesidad del querer recibe el nombre en la filosofía de Schelling de Selbstsucht en este escrito, y de un modo muy bonito está recogido también en las lecciones de Stuttgart. ${ }^{64}$ Ya en su Magisterexam habla de un «amor a sí» que nos separa de la voluntad general. El egoísmo es la tendencia «a sí»».

Puede que Nietzsche quiera invocar justamente ese egoísmo, ese amor así, pero es que es una posición personal distinta de la idea que hay detrás. Esta idea de libertad no obliga a una cosa u otra, esto es lo que justifica la crítica de ateísmo que Jacobi lanza a Schelling, y que éste no quiere reconocer.

5. Tesis: la libertad se ve obligada a rechazar todo lo finito, toda producción, a declarar la insuficiencia de todo lo determinado.

A mí me parece especialmente relevante en esta ocasión aquel grito del prólogo del Ecce Homo en el que avisa a que nos guardemos que no nos caiga encima una estatua. ${ }^{65}$ Porque me parece una imagen muy representativa e intuitiva de que ningún producto debe ser considerado culminante. Zaratustra le dice en este pasaje a sus creyentes que no le deben venerar, porque no se trata de venerar ninguna filosofía concreta, sino de ser sus propios señores. Ninguna expresión es última, ninguna determinación de la voluntad es última. Para la filosofía de la voluntad de poder sólo una cosa debe ser constante, la constancia ilimitada de este querer que quiere, destrozando con el martillo, lo que sea necesario destruir para seguir afirmándose a sí misma. Lo cual enlaza con el siguiente punto:

6. Tesis: hay una necesidad interna: el querer necesita querer efectivamente.

Para mostrar esta necesidad en Nietzsche hablaré del sacrilegio. Para no quedarnos con lo limitado (tesis 5) debemos ser capaz de profanar todo lo sagrado. Esta expresión la emplea Nietzsche cuando habla de la vergüenza que siente el que es glorificado. ${ }^{66} \mathrm{Y}$ ello para hacer valer que no hay nada que merezca ser glorificado, tampoco nada que podamos hacer, porque nada de lo que hagamos es merecedor de tal cosa. El sacrilegio, parece decir en estas líneas Nietzsche, es en sí mismo el glorificar, porque todo glorificar es inmerecido.

62 «Todo es necesidad - eso dice el nuevo conocimiento» HH I §107, OC III 121.

63 A $\$ 107$.

64 Cf. F.W. J. Schelling, Stuttgarter Privartvorlesungen, SW VII, 381; 438; 467.

65 EH Prefacio $\$ 4$.

66 Cf. CS $\$ 69$. 
7. Tesis: la libertad necesita del hombre.

Sólo el hombre puede ser propiamente libre. Lo que, según Nietzsche, significa que sólo él puede llegar a ser superhombre.

8. Tesis: esta libertad no se puede pensar salvo como indiferencia antes de su primer acto de decisión.

Antes de la gran decisión no hay dualidad. Poniendo ya el pie en la filosofía de Nietzsche, cabría decir: toda la dualidad de la filosofía nietzscheana es causa de la gran decisión. Moral de señores y de esclavos, superhombre y hombre decadente, voluntad de verdad o de poder, etc. La filosofía de Nietzsche es una filosofía de dualidades, como bien dice por ejemplo L. Polo; justamente -añadiría yo- porque lo que tematiza Nietzsche son las consecuencias de esa gran decisión. Si se hubiera parado a pensar en esa decisión originaria, en la voluntad de poder en sí misma, antes de ser activa, hubiera dicho que, entonces, deberíamos pensarla como una unidad inconcebible donde no se ha producido la diferenciación, y por ello, como una unidad indiferente. ${ }^{67}$ Pero Nietzsche no puede hacer tal cosa, no quiere introducirse libremente en ese fundamento abismal porque no le preocupa pensar la libertad, porque su filosofía de la decisión (como se denominó anteriormente) no es la de un filósofo de la libertad (como sí podría serlo Schelling), porque lo que él realiza es un voluntarismo vitalista. Esta es la razón -digamos especulativa- de la renuncia que M. Montinari comenta en su Nietzsches Nachlass 1885-1888 und der Wille zur Macht ${ }^{68}$ y que llevó a suprimir, en la actual edición crítica, la famosa Wille zur Macht presente por el contrario en los volúmenes IX y $\mathrm{X}$ de la Taschenausgabe (también había sido incluida posteriormente en los volúmenes XV y XVI de la Grossoktavausgabe).

De la comparativa Schelling-Nietzsche en estas ocho tesis fundamentales sobre la libertad extraída del escrito de la libertad de Schelling se podría deducir que las filosofías de ambos autores son, a pesar de sus diferencias, dos perspectivas diferentes e independientes sobre una intuición de libertad compartida. Schelling, lo que haría propiamente, como buen idealista, es desarrollar teóricamente esta intuición de libertad, el eje central de su sistema filosófico. Nietzsche, por su parte, enemigo de estas formas filosóficas, se desinteresa por el tratamiento teórico de esta intuición: su interés se centra decisivamente en sacarle rendimiento, en afrontar las consecuencias de esta intuición de libertad.

67 L. Polo parece encontrar esta unidad primigenia en la filosofía de Nietzsche en unos pasajes muy desconsiderados habitualmente por los críticos. Cf. L. Polo, Nietzsche como pensador de dualidades, Pamplona: EUNSA, 2005.

68 Cf. M. Montinari, «Nietzsches Nachlass 1885-1888 und der Wille zur Macht», en KSA XIV, pp. 398-400. 
Podríamos decir quizás que para Nietzsche analizar teóricamente esa intuición, pensarla detenidamente -lo que hace Schelling (y seguramente también lo que se ha hecho aquí en este trabajo) - paraliza, "mata", esta misma libertad que se está pensando, y justamente porque se la está pensando. ${ }^{69}$

No se trata pues tanto de que se rechace escépticamente una idea concreta de verdad. De lo que se trata es más bien de lo siguiente: esta libertad, tal y como está siendo intuida en Nietzsche y pensada en Schelling, debe «preferir» la incertidumbre a la verdad. Y esto lo habría visto Nietzsche mucho mejor que Schelling, seguramente porque Schelling no alcanza a percatarse de esta exigencia de su intuición de libertad. Bien podríamos sospechar, con Nietzsche, que lo que se esconde detrás de esa voluntad de verdad de Schelling, es cierto miedo a esa intuición de libertad qué él mismo quiere pensar. No es desde luego un miedo consciente, al menos no hasta el final: su rechazo a afrontar las consecuencias de su spinozismo dinámico ${ }^{70}$ le lleva a Weltalter que, aunque incompleta, le vinculan profundamente a Nietzsche, porque Dios deja de ser un sujeto extraño a la historia, para convertirse en un absoluto epocal ${ }^{71}$ que, en sentido propio no es nada. Esta nada es la que está siendo pensada como libertad. ${ }^{72}$

Aquí debemos recordar a Jacobi y su acusación de ateísmo. Jacobi sí se percató de que esa intuición de libertad, que según él también estaría funcionando en Fichte, llevaría a las dos hijas del criticismo kantiano, refiriéndose a la Wissenschaftslehre de Fichte y a la llamada por Jacobi Alleinsheitslehre de Schelling, son dos fases necesarias de este criticismo que desemboca, cuando uno extrae las consecuencias, en un «spinozismo invertido ${ }^{73}$ en la que se deja a Dios sin conciencia, sin personalidad y se lo deja de considerar como un ser distinto del mundo para considerarlo como el orden mismo del mundo. Schelling no acepta la acusación de Jacobi, como tampoco la había aceptado Fichte. Pero mucho me temo que lo que no acepten en realidad sean las consecuencias de su propia filosofía: el ateísmo.

Dios ha dejado de ser sustancia, para ser «querer originario», libertad. Si Schelling construye un sistema en el que las cosas, dejando de ser meras cosas, se han vuelto ellas mismas «suprasensibles» y el absoluto deja de ser un «sujeto trascendente»: ¿podemos seguir llamando Dios a ese Dios? Esta es la pregunta que le lanza Jacobi, la que se esconde tras la acusación de ateísmo. Es

69 La voluntad de verdad es al mismo tiempo, secretamente, una voluntad de muerte. Cf. FP III 40[39], y también FW §343.

70 En el que se sustituye la producción mecánica por das organische Hervorgebrachtes, y las «cosas» se llenan de vida.

71 A. Leyte, Las épocas de Schelling, Madrid: Akal, 1998, p. 15.

72 Ibid., p. 22.

73 F.H., Jacobi, Von der görtlichen Dingen, SW III, 347,354. 
la pregunta eludida. Pero seguramente la que hace que no se atreva a publicar, ni pueda acabar de pensar, su obra más importante: Weltalter. Por lo que respecta a Nietzsche, su filosofía, asumiendo que el ateísmo no es lo peligroso, desarrolla todas las consecuencias de una intuición de libertad semejante. Si el ser es querer, también la verdad debe ser en última instancia una «voluntad de verdad», y ésta, por ser voluntad, debería estar al servicio de la «voluntad de poder», que es un excelente nombre para un querer libre más allá del bien y del mal. Dicho con pocas palabras: pudiera ser que la voluntad de verdad que se esconde tras el esfuerzo conceptualizador de Schelling sea fruto del miedo a un mundo sin Dios.

No se trata desde luego de llegar a pensar que aquella voluntad de poder, ante la que el propio Nietzsche dio un paso atrás cuando quiso hablar de ella, llegara a decir algo parecido a, por ejemplo, lo que dice la filosofía de naturaleza o incluso el escrito de la libertad de Schelling. La voluntad de poder es, en realidad, otra cosa. Y lo es justamente porque sólo tiene sentido cuando lo que importa es desplegar las consecuencias de una intuición de libertad particular (compartida por ambos autores). Esta filosofía, recordemos el principio del Also Sprach Zarathustra, sólo puede tener su comienzo cuando se descubra que se ha matado a Dios. Sólo entonces se puede poner en cuestión el valor de verdad. ${ }^{74}$

La voluntad de poder es, dicho de otra manera, la forma que adquiere una intuición compartida cuando lo que nos interesa de esa intuición son sus consecuencias prácticas. Schelling no puede pensar lo mismo que Nietzsche, porque a él lo que le interesa es pensar esa intuición de libertad teóricamente, incluyéndola en un sistema idealista. Cabrían otros modos posibles de darle forma a esa misma intuición, por ejemplo, desde un enfoque hermenéutico, hablar del fundamento débil propio del pensiero debole de Vattimo. Diré más: Nietzsche sólo es posible porque es posible explorar pragmáticamente las consecuencias de una intuición sin necesidad de pensarla teóricamente.

\section{CONCLUSIÓN}

Schelling no se atreve a aceptar las consecuencias de haber convertido el ser originario en querer, es decir, no se atreve a poner en cuestión el valor de verdad. Cuando se sustituye la problemática de la verdad por la problemática del valor, se produce una consecuencia notable: se pasa de buscar la «verdad» a buscar «consecuencias». A Nietzsche no le interesa pensar la voluntad de poder para buscar su verdad (lo que no escaparía de la dialéctica de la voluntad de verdad), sino extraer las consecuencias para una interpretación de la libertad de la cual lo que interesa no es ya su verdad, sino justamente 
eso: sus consecuencias. Incluso Nietzsche lo tendría muy claro: esa voluntad de verdad sólo esconde miedo a la incertidumbre ${ }^{75}$, un miedo que es, ya Kant lo avisaba, especialmente mayúsculo cuando lo que está en juego es ¿qué es lo que debo hacer? Quiero decir, el miedo, la falta de valor, la vagueza, la cobardía de las que habla Kant en su Beantwortung der Frage: Was ist Aufklärung?, muestran cómo, en la práctica, sólo el miedo puede hacernos preferir la verdad (la del especialista, la de la ciencia, la del entendimiento/ conocimiento) en lugar de, como auténticos «mayores de edad», decidir con autonomía y en la incertidumbre lo que haremos. Nietzsche viene a extremar el voluntarismo kantiano. Si lo originario es el querer, la voluntad, entonces la misma verdad debe tener su fundamento en lo querido, y la verdad misma debe convertirse en un valor más, ni siquiera el más «bueno» ni el «preferible en todos los casos». Nietzsche se atreve a sacar las consecuencias de esto que los otros no consideran, porque en lugar de fijarse en las consecuencias prefirieron tematizar la cuestión teóricamente. Para llegar a esta conclusión, hemos tenido primeramente que analizar ambas filosofías. Se mostró que las filosofías de Nietzsche y Schelling se confeccionan independientemente la una de la otra, sin influencias, aun cuando fuese posible encontrar líneas comunes, como por ejemplo la dualidad Apolo-Dionisios en Nietzsche y la dualidad Produktivotät-Produkt en Schelling; en ambos casos una dualidad para expresar una fuerza creadora, construirende ${ }^{76}$ dirá Schelling, que avanza construyendo irrefrenablemente a través de lo solidificado (haciéndolo añicos cabría decir, ${ }^{77}$ según Nietzsche). Se descartó la tentativa de pensar que leer a Schelling pudiese servir para entender mejor lo que dice Nietzsche, y nos quedamos con la propuesta interpretativa de que descubrir una cercanía entre ambos autores iba más allá de destapar influencias y legados. La cercanía la encontrábamos, o proponíamos encontrar, en lo siguiente: ambos partían de una misma intuición de la libertad. Tan poderosa que hizo enmudecer ${ }^{78}$ a Schelling, temeroso de despertar las críticas de ateísmo. Tan intuitiva que Nietzsche no se atrevió nunca, e incluso dio un paso atrás, cuando quiso pensarla directamente al final de su vida. Schelling quería entender esa libertad, pensarla. Nietzsche la asumía, y quería enfrentarse a todo lo que la oprimiera.

Muy posiblemente, y frente a Schelling, quepa decir que esa nueva intuición de libertad exigía nuevas formas. Que por eso, Kierkeggard, Bakunin $26[301]$.

75 «La voluntad de verdad y de certeza provienen del miedo a la incertidumbre», FP III 590:

76 F.W. J. Schelling, Entwurf eines Systems der Naturphilosophie. AA I, 7, 78 (SW III, 12).

77 «De la piedra saltan pedazos: ¿qué me importa?» grita Nietzsche en EH «Así habló Zaratustra» $\S 8$, OC IV 842.

78 W. G. Jacobs, Schelling lesen, op. cit., p. 20. 
y todos los oyentes de Schelling ilusionados por su nueva filosofía, quedaban pronto decepcionados; por sus formas aún muy ilustradas. Era la antesala de un tiempo nuevo. Ambos coqueteaban con una nueva intuición de libertad que no tenía ya que ver con el mundo de las verdades, sino con el tiempo humano (el de los proyectos), la historia, el lenguaje y el arte.

Esa intuición de libertad, idealizada por Schelling y afirmada por Nietzsche estaría esperando aún un tipo de acceso adecuado, una formulación nueva sólo posible con un nuevo modo de hacer filosofía. Heidegger intentó ser justamente ese heraldo del nuevo tiempo, ese portavoz de una nueva intuición de libertad que exigía sobretodo pensar el tiempo y la historia. Fue sobre todo el segundo Heidegger, el Heidegger de la historia del ser quien, impulsado por la lectura de Nietzsche ${ }^{79}$ y buscando suelo teórico en Schelling, ${ }^{80}$ intentó hacer tal cosa. La valoración de este gesto exceden los propósitos de este estudio.

Sí diré, aunque a modo de comentario final, que resulta muy curioso el aislamiento de estos tres autores; quién sabe si promovido justamente por esta intuición de libertad. Pues al otro lado de esta intuición de libertad queda la humanidad del último hombre. Pudiera ser que sólo las pequeñeces de los «últimos hombres» ${ }^{81}$ nos salven de nuestra soledad. Ante la grandeza de la productividad que se esconde tras esa intuición de libertad, ante su poder, nada persiste, nada puede ser, todo sucumbe, todo es trivial. Acabamos por despreciar los productos, temerosos de que al «adorarlos» se desvanezca el lado dionisíaco de esta libertad. Esta intuición de libertad nos acaba conduciendo al espacio vacío que media «entre la soledad de las bestias y la soledad del Dios ${ }^{82}$, entre el cielo y la tierra.

79 Schelling y Nietzsche están muy presentes en el momento del conocido como giro heideggeriano.

80 Cf. A. Rojas, Das Potenzlose. Die Spür Schellings in der Spätphilosophie Heideggers, Hildesheim: Olms, 2014

81 «En este sentido es en el que Zaratustra llama a los buenos tanto "los últimos de los hombres" como "el principio del fin"; sobre todo los siente como la especie más dañina de hombre» EH «Por qué soy un destino» $\S 4$ (OC IV 855).

82 A. Carrasco, «El doble movimiento de la libertad. Fichte (1798) y Schelling (1809-1810)», Bajo palabra, II (2007), 143-47. 
